УДК 796.05

https://doi.org/10.36906/FKS-2021/42

Исмагилова Л.Ф., ORCID: 0000-0003- 0392-0534; Myтаева И.Ш., ORCID: 0000-0002-9387-7033, канд. биол. наук;

Шаймарданова Л.Ш., ORCID: 0000-0003-4130-9365

Елабужский институт (филиал) Казанского (Приволжского) федерального университета, г. Елабуга, Россия;

Кузнецова 3.M., ORCID: 0000-0002-5558-474X, канд. пед. наук

Университет управления «ТИСБИ»

2. Набережные Челны, Россия

\title{
СТРУКТУРА И СОДЕРЖАНИЕ ЗАНЯТИЯ ПО ФИЗИЧЕСКОЙ КУЛЬТУРЕ С ПРИМЕНЕНИЕМ НАРОДНЫХ ИГР В ВЫСШИХ УЧЕБНЫХ ЗАВЕДЕНИЯХ
}

Аннотация. В статье рассматривается структура и содержание элективных занятий по физической культуре высших учебных заведений. В ходе исследования были проанализированы структура и содержание занятия, проводимого в традиционном формате, и были проанализированы структура и содержания занятия по физической культуре с использованием на элективных занятиях народных игр в высших учебных заведениях.

Ключевые слова: народные игры, студенты, высшее учебное заведение, структура и содержания занятия.

Ismagilova L.F., ORCID: 0000-0003-0392-0534; Mutaeva I.Sh., ORCID: 0000-0002-9387-7033, Ph.D.; Shaimardanova L.Sh., ORCID: 0000-0003-4130-9365 Yelabuga Institute (branch) Kazan (Volga region) Federal University, Elabuga, Russia; Kuznetsova Z.M., ORCID: 0000-0002-5558-474X, PhD Institution of Management University "TISBI", Naberezhnye Chelny, Russia

\section{STRUCTURE AND CONTENT OF PHYSICAL EDUCATION LESSONS USING FOLK GAMES IN HIGHER EDUCATIONAL INSTITUTIONS}

Annotation. The article examines the structure and content of elective physical education classes in higher educational institutions. In the course of the research, the structure and content of the lesson conducted in the traditional format were analyzed, and the structure and content of the physical culture lesson with the use of elements of folk games in higher educational institutions were analyzed.

Keywords: folk games, students, higher educational institution, structure and content of the lesson.

Вопросы профессиональной подготовки будущих специалистов в условиях модернизации образования требуют особого внимания к физическому здоровью студентов. Для этого важно пересмотреть элементы содержания занятий по физической культуре. При этом большое значение имеет изменения работоспособности, как основа выбора структуры и содержания занятия. Схема изменения физической работоспособности студентов при реализации различных физических упражнений требует учета зон изменения работоспособности. 
Содержание занятия, по элективным дисциплинам (модулям) по физической культуре, представляет собой взаимосвязанные компоненты, которые, в свою очередь, включают в себя элементы содержания занятия. На рисунке 1, представлено содержание занятия по элективным дисциплинам (модулям) по физической культуре в высших учебных заведениях.

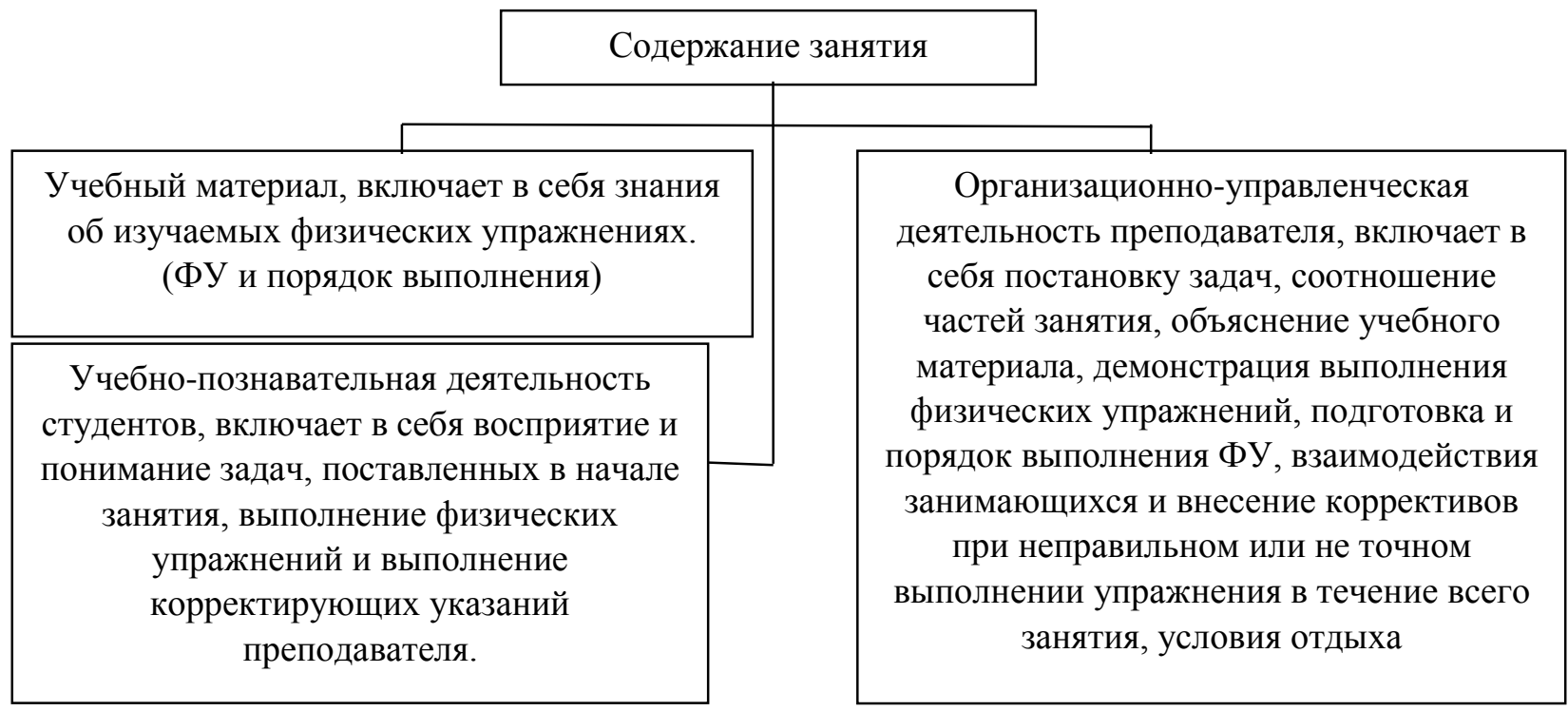

Рис. 1. Содержание занятия по физической культуре

Структура занятия, по элективным дисциплинам (модулям) по физической культуре, состоит из элементов, связанных между собой и обоснованных, которые обеспечивают функциональную связь всех элементов занятия.

Актуальна вариативность структуры занятия по физической культуре. В свою очередь, это позволяет учитывать поставленные задачи и специфику содержания занятия, а также рассмотреть возрастные особенности и уровень готовности студентов к усвоению и закреплению учебного материала. Существуют различные классификации занятий по физической культуре, где они - выстраивают, по определенной логики учебновоспитательный процесс. Основным условием взаимосвязи всех структурных компонентов занятия является изменения работоспособности занимающихся. На рисунке 2, представлена классификация занятий, по элективным дисциплинам (модулям) по физической культуре, применяемая в высших учебных заведениях.

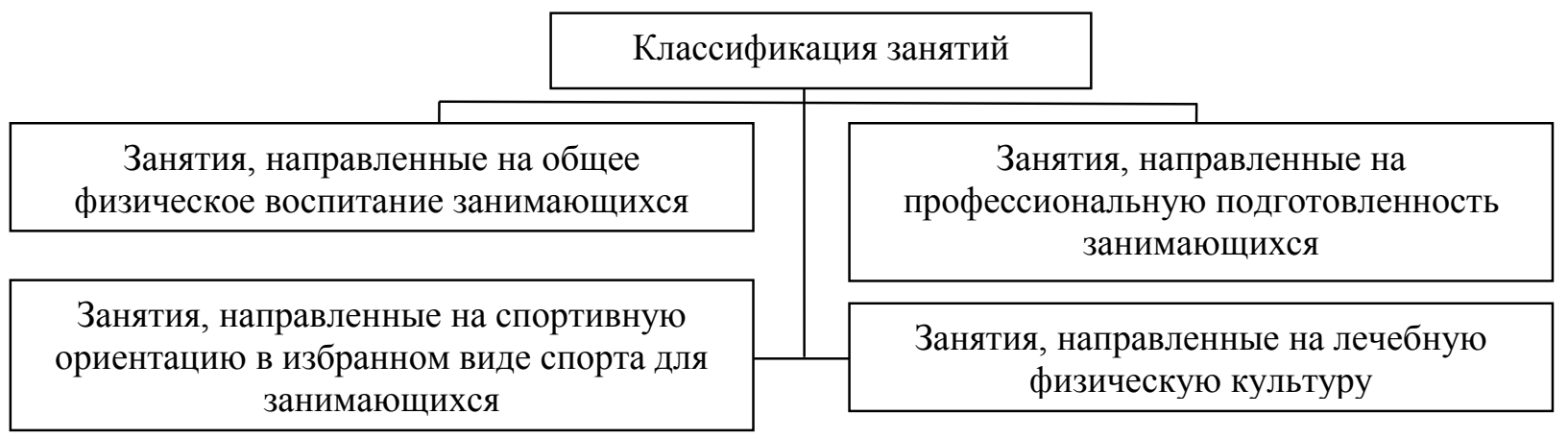

Рис. 2. Классификация занятий по физической культуре 
На рисунке 3, представлена структура занятия, по элективным дисциплинам (модулям) по физической культуре.

\begin{tabular}{|c|c|}
\hline Стр & анятия \\
\hline 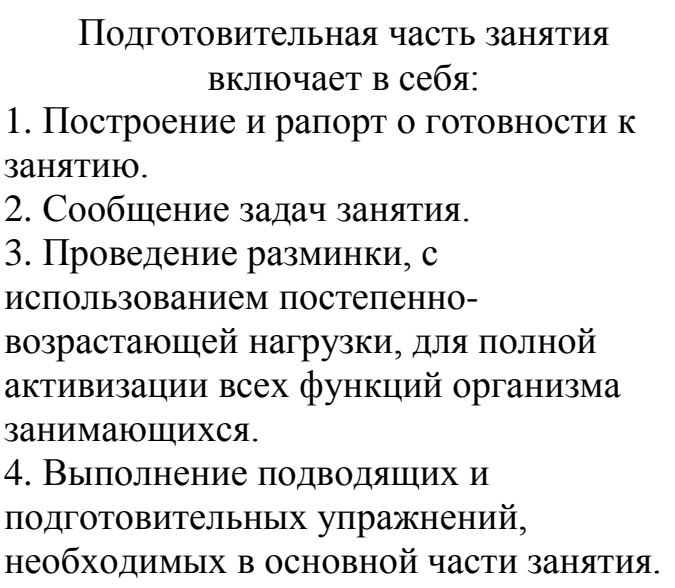 & $\begin{array}{l}\quad \text { Основная часть включает в себя: } \\
\text { 1. Совершенствование техники } \\
\text { изучаемого двигательного действия. } \\
\text { 2. Формирование у студентов } \\
\text { специальных знаний, развитие общих и } \\
\text { специальных двигательных качеств. } \\
\text { 3. Формирование личностных качеств } \\
\text { каждого занимающегося. } \\
\text { Содержание основной части исходит в } \\
\text { зависимости от изучаемого учебного } \\
\text { материала. }\end{array}$ \\
\hline $\begin{array}{l}\text { Заключительн } \\
\text { 1. Постепенное восстановление, выполне } \\
\text { 2. Использование народных подвижных } \\
\text { 3. Подведение итогов занятия. }\end{array}$ & $\begin{array}{l}\text { включает в себя: } \\
\text { ажнений на расслабление. }\end{array}$ \\
\hline
\end{tabular}

Рис. 3. Структура занятия по физической культуре

В зависимости от частей занятия происходят изменения общей физической работоспособности занимающихся, от перед рабочих сдвигов вырабатывания и уровень устойчивости и снижением работоспособности к концу занятия. Логическая схема изменения физической работоспособности на занятиях и в его частях является условием повышения и формирования высокого уровня физического потенциала здоровья занимающихся.

Проанализировав структуру и содержание элективного занятия по физической культуре, проводимого в традиционном формате и с использованием народных подвижных игр в течение всего занятия пришли к выводу о том, что средства народных игр позволяют повысить функциональный компонент подготовки. Содержание занятия, с использованием народных подвижных игр, в свою очередь, дополняется объемом и интенсивностью получаемой физической нагрузки различной величины и направленности в ходе реализации игрового метода. Применяя на элективном занятии народные подвижные игры как в подготовительной, основной, так и в заключительной части мы получаем эффективную динамику изменения физической работоспособности, психоэмоционального состояния, взаимодействия участников процесса на максимальном уровне. Народные игры считаются традиционным педагогическим средством и неотъемлемой частью национального, художественного и физического воспитания. Использование народных игр народов в физическом воспитании студентов в значительно большей мере оказывает положительное влияние на уровень физического и функционального состояния, физической подготовленности и состояния здоровья [2]. 
По содержанию все народные игры классически лаконичны, выразительны и доступны, формируется у занимающихся устойчивое, заинтересованное и уважительное отношение к культуре региона и всей страны в целом. Народные игры считаются основанием, на котором построены современные подвижные игры, которые используются не только на занятиях физической культуры, но и при подготовке спортсменов высокого уровня и класса [3].

Задачи, которые решаются народными играми при физическом воспитании студентов высших учебных заведениях, представлены на рисунке 4 [2].

Задачи, которые решаются народными играми при физическом воспитании и коррекции физического здоровья студентов ВУЗ

\begin{tabular}{|c|c|c|c|}
\hline $\begin{array}{c}\text { выработка умений использовать } \\
\text { физические упражнения в } \\
\begin{array}{c}\text { условиях внешней среды, в том } \\
\text { числе в трудовой и } \\
\text { профессиональной деятельности }\end{array}\end{array}$ & $\begin{array}{c}\text { формирование } \\
\text { разносторонней } \\
\text { физической } \\
\text { подготовленности }\end{array}$ & $\begin{array}{c}\text { формирование самооценки } \\
\text { личности, уверенности в } \\
\text { своих силах, } \\
\text { нравственного } \\
\text { самосознания и } \\
\text { мировоззрения }\end{array}$ \\
\begin{tabular}{|c|c|c|} 
поэтапная подготовка к \\
выполнению комплекса ГТО и \\
участия в массовых видах спорта
\end{tabular} & $\begin{array}{c}\text { повышение интереса студентов к занятиям, } \\
\text { использование в своей практической } \\
\text { деятельности элементы народных игр. }\end{array}$ \\
\hline
\end{tabular}

Рис. 4. Задачи, решаемые средствами народных игр при занятиях студентов в высших учебных заведениях

Народные игры в своем большинстве проводятся на свежем воздухе, особенно в весенне-осенние периоды, поэтому они без сомнения могут стать корректирующим средством физического здоровья и повысить устойчивость организма студентов к вредным проявлениям внешней среды [1].

Таким образом, народные подвижные игры достаточно многообразны и издавна служат средством самопознания, поскольку именно в них проявляются не только физические возможности, но и такие личностные качества как доброта, благородство и взаимовыручка. Народные игры направлены на развитие определенных физических качеств и содержат воспитательный аспект, который связан со становлением личности студентов. Реализация средств народных игр на занятиях студентами позволяет реализовать образовательные, оздоровительные и воспитательные задачи, как основа получения условий формирования человеческого потенциала в виде повышения уровня физического развития и физической подготовленности с учетом исходного состояния здоровья.

\section{Литература}

1. Земцов П.С. Физическая культура в вузе как средство формирования здорового образа жизни студентов // Молодой ученый. 2018. № 38 (224). С. 183-187.

2. Пономарев В.В., Маркелов А.В. Прикладная направленность народных состязаний в физическом воспитании студентов вуза // Теория и практика физ. культуры. 2014. № 12. С. $72-$ 73.

3. Кикотия В.Я., Барчукова И.С. Физическая культура и физическая. М.: Юнити, 2017. $288 \mathrm{c}$.

(С) Исмагилова Л.Ф., Мутаева И.Ш., Шаймарданова Л.Ш., Кузнеияова 3.М., 2021 